\title{
Infarct Volume Predicts Hospitalization Costs in Anterior Circulation Large-Vessel Occlusion Stroke
}

\author{
(D)C.D. Streib, (1) S. Rangaraju, (DD.T. Campbell, (DD.G. Winger, (D).L. Paolini, (D)A.J. Zhang, (D) B.T. Jankowitz, (D)A.P. Jadhav, and \\ (i) T.G. Jovin \\ O- $\equiv$
}

\begin{abstract}
BACKGROUND AND PURPOSE: Anterior circulation large-vessel occlusion stroke, one of the most devastating stroke subtypes, is associated with substantial economic burden. We aimed to identify predictors of increased acute care hospitalization costs associated with anterior circulation large-vessel occlusion stroke.
\end{abstract}

MATERIALS AND METHODS: Comprehensive cost-tracking software was used to calculate acute care hospitalization costs for patients with anterior circulation large-vessel occlusion stroke admitted July 2012 to October 2014. Patient demographics and stroke characteristics were analyzed, including final infarct volume on follow-up neuroimaging. Predictors of hospitalization costs were determined using multivariable linear regression including subgroup cost analyses by treatment technique (endovascular, IV tPA-only, and no reperfusion therapy) and sensitivity analyses incorporating patients initially excluded due to early withdrawal of care.

RESULTS: Three hundred forty-one patients (median age, 69 years; interquartile range, 57-80 years; median NIHSS score, 16; interquartile range, 13-21) were included in our primary analysis. Final infarct volume, parenchymal hematoma, baseline NIHSS score, ipsilateral carotid stenosis, age, and obstructive sleep apnea were significant predictors of acute care hospitalization costs. Final infarct volume alone accounted for $20.87 \%$ of the total cost variance. Additionally, final infarct volume was consistently the strongest predictor of increased cost in primary, subgroup, and sensitivity analyses.

CONCLUSIONS: Final infarct volume was the strongest predictor of increased hospitalization costs in anterior circulation large-vessel occlusion stroke. Acute stroke therapies that reduce final infarct volume may not only improve clinical outcomes but may also prove cost-effective.

ABBREVIATIONS: ACLVO = anterior circulation large-vessel occlusion; EWOC = early withdrawal of care; FIV = final infarct volume; IQR = interquartile range; $\mathrm{mTICl}=$ modified $\mathrm{TICl}$ score; $\mathrm{PHI}=$ parenchymal hematoma type $1 ; \mathrm{PH} 2$ = parenchymal hematoma type 2

$\mathrm{t}$ is estimated that direct medical costs for stroke treatment in the United States in 2015 reached $\$ 38$ billion and will rise to

Received April 26, 2018; accepted after revision October 21.

From the Department of Neurology (C.D.S., A.J.Z.), University of Minnesota, Minneapolis, Minnesota; Department of Neurology, Stroke Institute (C.D.S., S.L.P., B.T.J., A.P.J., T.G.J., S.R., D.T.C.), University of Pittsburgh Medical Center, Pittsburgh. Pennsylvania; Department of Neurology (S.R.), Emory University, Atlanta, Georgia; Department of Neurology (D.T.C.), WellStar Kennestone Hospital, Marietta, Georgia; and Clinical Translational Science Institute (D.G.W.), University of Pittsburgh, Pittsburgh, Pennsylvania.

Dr Streib was a NIH StrokeNET fellow supported by 1U01NS086489-02 (Principal Investigator Tudor G. Jovin and Lawrence Wechsler). Dr Rangaraju was a National Institutes of Health StrokeNET fellow supported by 1U10NS086607-01 (Principal Investigator, Michael Frankel) and is also a recipient of a clinical research training fellowship from the American Brain Foundation.

This project was supported by the National Institutes of Health through grant No. UL1-TR-000005.

Data previously presented as a platform presentation at: International Stroke Conference, February 22-24, 2017; Houston, Texas.

Please address correspondence to Tudor G. Jovin, MD, UPMC Stroke Institute, 200 Lothrop St, Suite C-400, Pittsburgh, PA 15213; e-mail: jovitg@upmc.edu; @PittStroke
\$51.3 billion in 2020. ${ }^{1}$ Large-vessel occlusion stroke, one of the most clinically devastating stroke subtypes, is believed to drive acute hospitalization costs in a disproportionate manner relative to other ischemic stroke etiologies. ${ }^{2,3}$ Recent advances in endovascular treatment for anterior circulation large-vessel occlusion (ACLVO) stroke have dramatically improved functional outcomes, ${ }^{4-10}$ with the unintended consequence of concentrating acute ACLVO stroke care and the corresponding health care expenses in select tertiary referral hospitals. The economic burden to these hospitals is an especially timely consideration.

Prior studies addressing the cost of hospitalization in ischemic stroke have found that endovascular treatment, intubation, baseline NIHSS, atrial fibrillation, ischemic heart disease, stroke sub-

\footnotetext{
-- Indicates open access to non-subscribers at www.ajnr.org

$\equiv$ Indicates article with supplemental on-line tables.

Indicates article with supplemental on-line photos.

http://dx.doi.org/10.3174/ajnr.A5917
} 
type, diabetes mellitus, age, sex, and dehydration are significant predictors of stroke hospitalization costs. ${ }^{11-16}$ Hospitalization costs are typically calculated from billing charges, diagnostic codes, and insurer or Medicare payments. However, such indirect accounting methods do not accurately reflect the true cost of delivering medical care from the perspective of the hospital. ${ }^{15-18}$ In July 2012, the University of Pittsburgh Medical Center (UPMC) implemented proprietary, comprehensive cost-tracking software, which captures hospitalization costs with considerably greater patient-level detail than traditional methods. ${ }^{19}$ Our aim was to use this data capture paradigm to determine critical predictors of hospitalization costs in ACLVO stroke.

\section{MATERIALS AND METHODS}

Data Sources and Subjects

Institutional review board approval was obtained. Our patient cohort was derived from 2 prospectively collected databases: our Get With The Guidelines stroke data base and our endovascular stroke data base. Patients with acute stroke presenting to our hospital with a primary diagnosis of ACLVO stroke between July 2012 and September 2014 were eligible for analysis. To avoid confounding, we restricted the analysis to patients receiving intensive medical treatment. Withdrawal of care leading to discharge or death within the first week of hospitalization constituted an exclusion criterion. Patients with lack of follow-up imaging or extended hospitalization due to factors unrelated to stroke were also excluded.

Patient demographics, medical history, admission laboratory values, medications, stroke characteristics, and neuroimaging findings were incorporated into the analysis. Stroke characteristics and neuroimaging findings included the following: affected hemisphere, baseline NIHSS score, level of arterial occlusion, final infarct volume (FIV), parenchymal hematoma type 1 (PH1), and parenchymal hematoma type 2 ( $\mathrm{PH} 2)$. Etiologic factors such as underlying atrial fibrillation, ipsilateral carotid stenosis, and carotid dissection were also studied. The primary reperfusion technique was classified as endovascular treatment, IV tPA, or no reperfusion therapy; patients who received both endovascular treatment and IV tPA were analyzed as having endovascular treatment.

\section{Measurements}

The level of occlusion was defined as the extracranial internal carotid artery, intracranial internal carotid artery, middle cerebral artery M1 division, middle cerebral artery M2 division, or tandem lesions, as determined by catheter-based angiography when available or the initial vessel imaging study (CTA or MRA). The Alberta Stroke Program Early CT Scores were interpreted by the attending vascular neurologist and recorded at the time of admission for patients undergoing endovascular therapy. Revascularization status, the modified Thrombolysis in Cerebral Infarction score (mTICI), was assessed by the interventionalist post-endovascular treatment and prospectively recorded. FIV was calculated on MR imaging or CT scans obtained 6-48 hours postadmission by measuring the infarct volume on each slice and then summating the infarct volumes of the individual slices according to previously published methodology. ${ }^{20}$ We have demonstrated high correlation between infarct volumes calculated by CT and MR imaging within our database in prior studies. ${ }^{20}$

\section{Cost Analysis}

Our institution developed novel, automated comprehensive costtracking software, which was implemented July 1, 2012. The cost algorithms of the software incorporate patient-level information to generate individualized patient-level cost data for each admission. For example, rather than assigning a uniform cost to all "stroke protocol" brain MR imaging scans, costs are calculated by MR imaging acquisition time. Accordingly, MR imaging scans with longer acquisition times are assigned a higher cost value, which accounts for the increased nursing and MR imaging technician resources required, as well as the depreciation of the MR imaging scanner (simplified equation: Cost $_{\mathrm{MRI}}=($ MRI Tech Salary $\times$ Time $\left._{\mathrm{MRI}}\right)+\left(\right.$ Nurse Salary $\times$ Time $\left._{\mathrm{MRI}}\right)+($ MRI Depreciation $\times$ Time $_{\mathrm{MRI}}$ ). This calculation differentiates the cost of MR imaging for an uncooperative, aphasic patient with a high NIHSS score versus a cooperative patient with a low NIHSS score. This level of detail is captured across all hospital cost domains, including the following: supplies, drugs, blood products, clinical ancillary services, diagnostic testing, imaging, laboratory, dietary, intensive care unit nursing, non-intensive care unit nursing, pharmacy, surgical services, housekeeping, and miscellaneous expenses, which were included in our analysis. Costs were calculated from the hospital's perspective and encompass the duration of the patient's acute care hospitalization. Hospitalization costs were analyzed objectively, independent of reimbursement considerations.

Physicians' costs as calculated by our software were highly variable because of differences in physicians' salaries and the source of physicians' salary support. These costs did not accurately correlate with the levels of service provided. To avoid introducing imprecision into the analysis, we excluded physicians' costs. Similarly, transfer costs, which occur randomly, and indirect costs, such as administrative salaries of nonhealth care providers, were also excluded. We did not adjust for inflation because the study duration was limited to a 28 month period.

\section{Statistical Analysis}

Distributions of continuous variables were assessed for normality. We performed a log-transformation of the hospital cost data to correct for rightward skewing. All baseline demographics and stroke characteristics were included in univariate analyses. Variables with a $P$ value $<.25$ in univariate linear regression analyses were entered into multivariable linear regression to determine base cost models. Variables with a $P$ value $<.05$ in multivariable linear regression were considered statistically significant. The final model was evaluated for heteroscedasticity graphically by plotting the fitted-versus-residual values for each subject and formally using the Breusch-Pagan test. If the variance inflation factor was $>2$, it would be addressed by removing the less biologically plausible variable from the model. The goodness-of-fit of the models was assessed by $R^{2}$. For ease of interpretation, $\beta$ coefficients of each statistically significant variable were exponentiated. Following this reverse transformation, the exponentiated $\beta$ coefficients represent the percentage change in hospitalization costs 


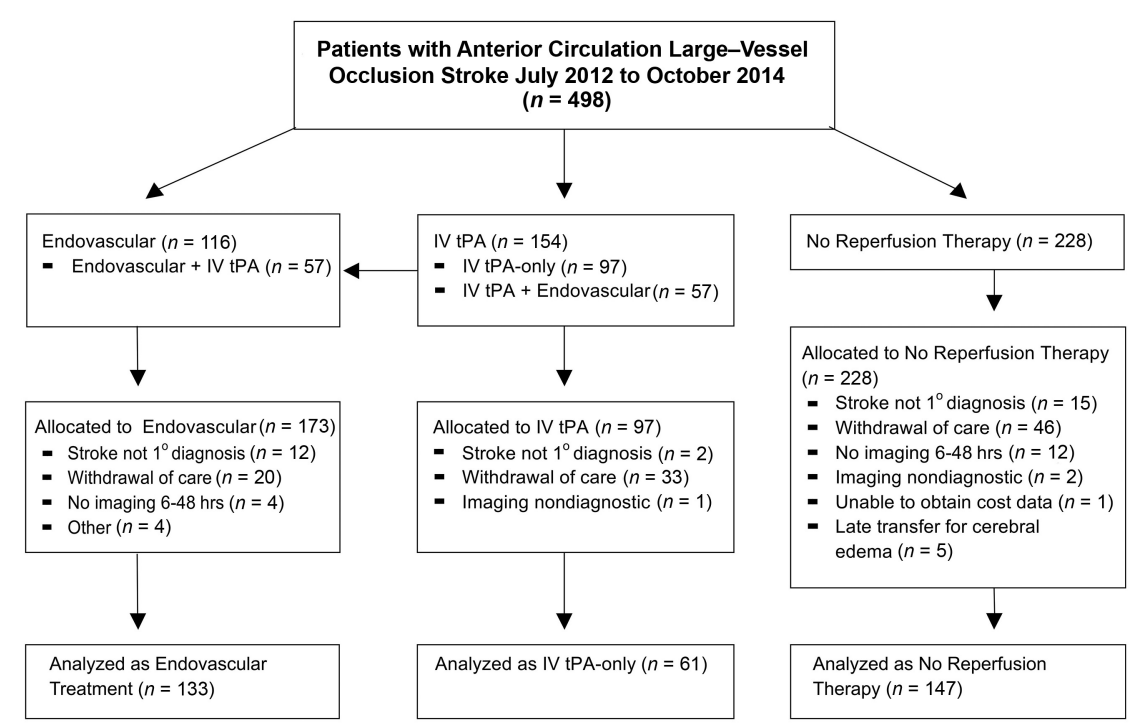

FIG 1. Study flow diagram. Endovascular stroke data base July 2014 to October 2014: three hundred twenty-four total stroke interventions (66 posterior circulation, 88 at an affiliated hospital without cost-tracking) with 173 patients eligible for anterior circulation large-vessel occlusion.

\section{Primary Analysis}

Results from our univariate analysis (On-line Table 1) guided construction of our best-fit model using multivariable linear regression. In the primary analysis of all patients with ACLVO while controlling for the primary reperfusion technique, significant predictors of logtransformed hospitalization costs included the following: FIV $(P<0.001)$; the composite variable $\mathrm{PH} 1$ or $\mathrm{PH} 2$ $(P<.001)$; baseline NIHSS score $(P=$ $.002)$; obstructive sleep apnea $(P=$ $.0040)$; age $(P=.009)$; and ipsilateral carotid stenosis $(P=.020)$. Age was the only variable that was inversely associated with hospitalization costs. The final model explained $42.07 \%$ of the variance in hospitalization costs $\left(R^{2}=42.07 \%\right)$. The FIV was identified as the strongest predictor of hospitalization costs, accounting for $20.87 \%$ of the total hospi-

attributable to a 1-unit increase of each continuous variable or the percentage change associated with the presence of a categorical variable. Within each model, the magnitude of the effect size of each variable was quantified by partial eta ${ }^{2}$.

Because endovascular treatment and IV tPA administration are proven predictors of increased hospitalization costs, ${ }^{11,15,16}$ the primary analysis was performed on all eligible patients with ACLVO while controlling for treatment technique (endovascular, IV tPA-only, and no reperfusion therapy) by including treatment technique in the multivariable linear regression model. We then performed subgroup analyses on each treatment arm. Finally, we performed sensitivity analyses incorporating previously excluded patients to assess the robustness of our findings. The statistical analysis was conducted with STATA software, Version 13.0 (StataCorp, College Station, Texas).

\section{RESULTS}

Of the 498 patients who presented to our institution with an ACLVO stroke during the study period, 345 patients met the general inclusion criteria. Of those patients, 4 were excluded because their hospitalization was prolonged $>21$ days for reasons unrelated to stroke (myotonic dystrophy $=1$, alcohol withdrawal $=1$, delayed discharge placement $=2$ ). Three hundred forty-one patients were included in the primary analysis and comprised 133 patients with endovascular treatment, 61 patients with IV tPAonly, and 147 patients who received no reperfusion therapy (Fig 1). Median hospitalization costs were $\$ 21,871$ (interquartile range [IQR], \$15,672-\$31,363) for the endovascular therapy group, $\$ 14,456$ (IQR, $\$ 7626-\$ 19,701$ ) for the IV tPA-only group, and $\$ 13,401$ (IQR, $\$ 8308-\$ 23,589$ ) for the no reperfusion therapy group. The median age of our cohort was 69 years (IQR, 57-80 years) with a median baseline NIHSS score of 16 (IQR, 13-21). Complete patient demographics and stroke characteristics are summarized in Tables 1 and 2, respectively. talization cost variance as calculated by partial eta ${ }^{2}$. The variables did not demonstrate significant collinearity, nor did the model have heteroscedasticity in the primary or subgroup analyses.

\section{Subgroup Analysis}

The FIV was the only variable that remained statistically significant across all subgroup models. Irrespective of the treatment technique, FIV was the strongest predictor of hospitalization costs as determined by partial eta ${ }^{2}$. $\mathrm{PH} 1$ or the related composite variable, PH1 or PH2, were strongly correlated with cost in all except the IV tPA-only subgroup, as was obstructive sleep apnea. The baseline NIHSS score was a significant predictor in all models with the exception of the subgroup with no reperfusion therapy. Ipsilateral carotid stenosis and the mTICI score were statistically significant predictors of cost for the endovascular treatment subgroup only, while age was inversely associated with cost in the subgroup with no reperfusion therapy. The $P$ values and exponentiated $\beta$ coefficients of the statistically significant variables for each model are summarized in Table 3.

\section{Sensitivity Analysis}

Of the 99 patients excluded from the primary and subgroup analyses due to early withdrawal of care (EWOC), complete data were available for 88 patients. EWOC led to significantly lower hospitalization cost (median, $\$ 6664$; IQR, $\$ 4868-\$ 13,765$ ) compared with aggressive medical and interventional treatment $(P<.0001)$. Patients with EWOC were older, with larger infarct volumes, higher baseline NIHSS scores, and increased rates of PH1 and PH2 (On-line Table 2). When patients with EWOC were included, age, FIV, and PH1 remained significant predictors of cost, but the model had a considerably poorer fit $\left(R^{2}=30.10 \%\right)$ and the association among cost, FIV, and PH1 was attenuated due to confounding. Accounting for EWOC status generated a considerably more robust model $\left(R^{2}=\right.$ 42.53) in which FIV, followed by PH1, remained consistently strong predictors of increased hospitalization cost (On-line Table 3). 
Table 1: Baseline patient demographics ${ }^{a}$

\begin{tabular}{|c|c|c|c|c|}
\hline & $\begin{array}{l}\text { All Patients } \\
(n=341)\end{array}$ & $\begin{array}{l}\text { Endovascular Therapy } \\
\qquad(n=133)\end{array}$ & $\begin{array}{l}\text { IV tPA-Only } \\
(n=61)\end{array}$ & $\begin{array}{l}\text { No Reperfusion Therapy } \\
\qquad(n=147)\end{array}$ \\
\hline Cost (median) (IQR) & $\begin{array}{c}\$ 16,446 \\
(\$ 9823-\$ 27,165)\end{array}$ & $\begin{array}{c}\$ 21,871 \\
(\$ 15,672-\$ 31,363)\end{array}$ & $\begin{array}{c}\$ 14,456 \\
(\$ 7626-\$ 19,701)\end{array}$ & $\begin{array}{c}\$ 13,401 \\
(\$ 8308-\$ 23,589)\end{array}$ \\
\hline Age (median) (IQR) & $69(57-80)$ & $68(58-80)$ & $75(59-83)$ & $66(55-79)$ \\
\hline Female & 165 (48.4\%) & 65 (48.9\%) & $33(54.1 \%)$ & $67(45.6 \%)$ \\
\hline A. Fib & $162(47.5 \%)$ & $65(48.9 \%)$ & $37(60.7 \%)$ & $60(40.9 \%)$ \\
\hline Alcohol abuse & $27(7.9 \%)$ & $7(5.3 \%)$ & $4(6.6 \%)$ & $16(10.9 \%)$ \\
\hline Anticoagulation & $29(8.5 \%)$ & $11(8.3 \%)$ & $5(8.2 \%)$ & $13(8.8 \%)$ \\
\hline$C A D$ & $78(23.0 \%)$ & $26(19.6 \%)$ & $19(31.7 \%)$ & $33(22.6 \%)$ \\
\hline CAS & $72(21.1 \%)$ & $23(17.3 \%)$ & $10(16.4 \%)$ & $39(26.5 \%)$ \\
\hline $\mathrm{CHF}$ & 59 (17.5\%) & $15(11.4 \%)$ & $17(28.3 \%)$ & 27 (18.5\%) \\
\hline CKD & $19(5.6 \%)$ & $3(2.3 \%)$ & $4(6.7 \%)$ & $12(8.2 \%)$ \\
\hline Dementia & $15(4.4 \%)$ & $2(1.5 \%)$ & $7(11.7 \%)$ & $6(4.1 \%)$ \\
\hline Dissection & $17(5.0 \%)$ & $9(6.8 \%)$ & $2(3.3 \%)$ & $6(4.1 \%)$ \\
\hline DMII & $103(30.2 \%)$ & $51(38.3 \%)$ & $25(41.0 \%)$ & 27 (18.4\%) \\
\hline Hyperlipidemia & $149(43.7 \%)$ & 64 (48.1\%) & 29 (47.5\%) & $56(38.1 \%)$ \\
\hline Hypertension & $291(85.3 \%)$ & 111 (83.5\%) & 55 (90.2\%) & $125(85.0 \%)$ \\
\hline Illicit drug use & $8(2.3 \%)$ & $0(0.0 \%)$ & $0(0.0 \%)$ & $8(5.5 \%)$ \\
\hline Obesity & $44(12.9 \%)$ & $12(9.0 \%)$ & $19(31.1 \%)$ & $13(8.8 \%)$ \\
\hline OSA & $31(9.2 \%)$ & $12(9.0 \%)$ & $8(13.1 \%)$ & $11(7.5 \%)$ \\
\hline Psychiatric & $33(9.7 \%)$ & $9(6.8 \%)$ & $7(11.5 \%)$ & $17(11.6 \%)$ \\
\hline Tobacco & $124(36.6 \%)$ & $40(30.1 \%)$ & $21(34.4 \%)$ & $63(42.9 \%)$ \\
\hline
\end{tabular}

Note:-A. Fib indicates atrial fibrillation; CAD, coronary artery disease; Dissection, ipsilateral carotid dissection; CAS, ipsilateral carotid artery stenosis; CHF, congestive heart failure; CKD, chronic kidney disease; DMII, diabetes mellitus II; OSA, obstructive sleep apnea; Psychiatric, any psychiatric comorbidity.

${ }^{a}$ Values represent total number and percentage unless otherwise indicated.

Table 2: Stroke characteristics ${ }^{\mathrm{a}}$

\begin{tabular}{|c|c|c|c|c|}
\hline & $\begin{array}{l}\text { All Patients } \\
(n=341)\end{array}$ & $\begin{array}{l}\text { Endovascular Therapy } \\
\qquad(n=133)\end{array}$ & $\begin{array}{l}\text { IV tPA-Only } \\
(n=61)\end{array}$ & $\begin{array}{l}\text { No Reperfusion } \\
\text { Therapy }(n=147)\end{array}$ \\
\hline Baseline NIHSS (median) (IQR) & $16(13-21)$ & $16(13-19)$ & $16(12-22)$ & $17(13-21)$ \\
\hline FIV (mL) (median) (IQR) & $59.9(17.1-129)$ & $27(9.4-86.0)$ & $62.5(8.7-118.7)$ & $93(37.8-170.0)$ \\
\hline Left hemisphere & $175(51.3 \%)$ & $65(48.9 \%)$ & $38(62.3 \%)$ & $72(48.9 \%)$ \\
\hline \multicolumn{5}{|l|}{ Level of occlusion } \\
\hline Extracranial ICA & $7(2.0 \%)$ & $2(1.5 \%)$ & $4(6.6 \%)$ & $1(0.6 \%)$ \\
\hline Tandem occlusion & $39(11.4 \%)$ & $31(23.3 \%)$ & $2(3.3 \%)$ & $6(4.1 \%)$ \\
\hline Intracranial ICA & $79(23.2 \%)$ & $16(12.0 \%)$ & $9(14.8 \%)$ & $54(36.7 \%)$ \\
\hline Ml division of MCA & $166(48.7 \%)$ & $74(55.6 \%)$ & $33(54.1 \%)$ & $59(40.1 \%)$ \\
\hline M2 division of MCA & $50(14.7 \%)$ & $10(7.5 \%)$ & $13(21.3 \%)$ & $27(18.4 \%)$ \\
\hline $\mathrm{PH}$ & $14(4.1 \%)$ & $3(2.3 \%)$ & $8(13.1 \%)$ & $4(2.7 \%)$ \\
\hline $\mathrm{PH} 2$ & $9(2.6 \%)$ & $5(3.8 \%)$ & $3(4.9 \%)$ & $1(0.7 \%)$ \\
\hline ASPECTS (median) (IQR) & Data unavailable & $8(7-9)$ & Data unavailable & Data unavailable \\
\hline Wake-up stroke & Data unavailable & $19(14.3 \%)$ & Data unavailable & Data unavailable \\
\hline Onset to treatment (min) (median) (IQR) & & $310(236-465)$ & $138(115-155)$ & \\
\hline IA intubation & & $5(3.7 \%)$ & & \\
\hline \multicolumn{5}{|l|}{ Recanalization (mTICI) } \\
\hline $\mathrm{mTICI} 0$ & & $1(0.8 \%)$ & & \\
\hline $\mathrm{mTICl} 1$ & & $1(0.8 \%)$ & & \\
\hline $\mathrm{mTICl} 2 \mathrm{a}$ & & $4(3.0 \%)$ & & \\
\hline $\mathrm{mTICI} 2 \mathrm{~b}$ & & $91(68.7 \%)$ & & \\
\hline $\mathrm{mTICl} 3$ & & $36(26.9 \%)$ & & \\
\hline
\end{tabular}

Note:-IA indicates intra-arterial (ie, endovascular treatment).

${ }^{a}$ Values represent total number and percentage unless otherwise indicated.

A second sensitivity analysis included 11 of 12 patients whose follow-up imaging was performed outside our prespecified 6- to 48-hour time window. Statistically significant predictors of hospitalization costs were identical to those in the primary analysis (On-line Table 3).

\section{DISCUSSION}

We found that in patients with ACLVO stroke, FIV, a well-known predictor of clinical outcome, ${ }^{8,9,21,22}$ is also the most robust determinant of hospitalization costs. FIV had the strongest association with hospitalization costs in univariate analysis (Fig 2), a relationship that persisted in all multivariable analyses, including our primary analysis of all patients with ACLVO and subgroup analyses of patients with endovascular therapy, IV tPA, or no reperfusion therapy. Although it is intuitive that larger stroke volumes lead to more resource-intensive hospital admissions, we do not believe that this fundamental relationship between infarct volume and hospitalization costs has been previously reported.

We constructed our cost-prediction models from baseline patient demographics and stroke characteristics alone. Given that we limited our models to variables with $P$ values $<.05$ and inten- 
Exponentiated $\boldsymbol{\beta}$-Coefficient $(95 \% \mathrm{Cl})^{\mathrm{b}}$

\begin{tabular}{|c|c|c|c|}
\hline \multicolumn{4}{|c|}{ Primary analysis: all $\mathrm{ACLVO}^{\mathrm{a}}(n=341)$} \\
\hline $\mathrm{FIV}(\mathrm{mL})$ & $<.0001$ & $20.87 \%$ & $1.0037(1.0029-1.0048)$ \\
\hline PH types 1 and 2 & $<.0001$ & $5.22 \%$ & $1.6399(1.3050-2.0610)$ \\
\hline NIHSS & .0024 & $2.76 \%$ & $1.0161(1.0057-1.0266)$ \\
\hline Obstructive sleep apnea & .0040 & $2.48 \%$ & $1.3391(1.0981-1.6329)$ \\
\hline Age (yr) & .0089 & $2.06 \%$ & $0.9946(0.9906-0.9986)$ \\
\hline Ipsilateral carotid stenosis & .0195 & $1.65 \%$ & 1.1902 (1.0285-1.3774) \\
\hline \multicolumn{4}{|c|}{ Subgroup analysis by treatment group } \\
\hline \multicolumn{4}{|c|}{ Endovascular therapy $(n=133)$} \\
\hline $\mathrm{FIV}(\mathrm{mL})$ & .0003 & $10.03 \%$ & 1.0024 (1.0011-1.0037) \\
\hline PH type 1 & .0006 & $9.24 \%$ & $2.4942(1.4926-4.1680)$ \\
\hline Obstructive sleep apnea & .0018 & $7.71 \%$ & $1.5211(1.1727-1.9730)$ \\
\hline NIHSS & .0120 & $5.08 \%$ & $1.0206(1.0046-1.0368)$ \\
\hline Ipsilateral carotid stenosis & .0290 & $3.85 \%$ & $1.2481(1.0234-1.5221)$ \\
\hline $\mathrm{mTICl}$ score $\mathrm{c}^{\mathrm{C}}$ & .0364 & $1.79 \%$ & Multilevel variable \\
\hline \multicolumn{4}{|l|}{ IV tPA-only $(n=61)$} \\
\hline $\mathrm{FIV}(\mathrm{mL})$ & $<.0001$ & $29.11 \%$ & $1.0043(1.0025-1.0060)$ \\
\hline NIHSS & .0300 & $7.99 \%$ & $1.0273(1.0273-1.0524)$ \\
\hline \multicolumn{4}{|c|}{ No reperfusion therapy $(n=147)$} \\
\hline $\mathrm{FIV}(\mathrm{mL})$ & $<.0001$ & $27.92 \%$ & $1.0042(1.0031-1.0053)$ \\
\hline PH types 1 and 2 & .0005 & $8.37 \%$ & $2.6371(1.5458-4.4988)$ \\
\hline Obstructive sleep apnea & .0300 & $3.29 \%$ & $1.5057(1.0407-2.1784)$ \\
\hline Age (yr) & .0330 & $3.20 \%$ & $0.9925(0.9857-0.9937)$ \\
\hline
\end{tabular}

a Controlled for treatment type: endovascular, IV-tPA, and no reperfusion therapy.

${ }^{\mathrm{b}}$ The exponentiated $\beta$-coefficient represents the multiplicative change in cost associated with an increase in 1 unit of a continuous variable (or the presence of a categoric variable), while holding all other variables constant.

cMultilevel variable with F-distribution.

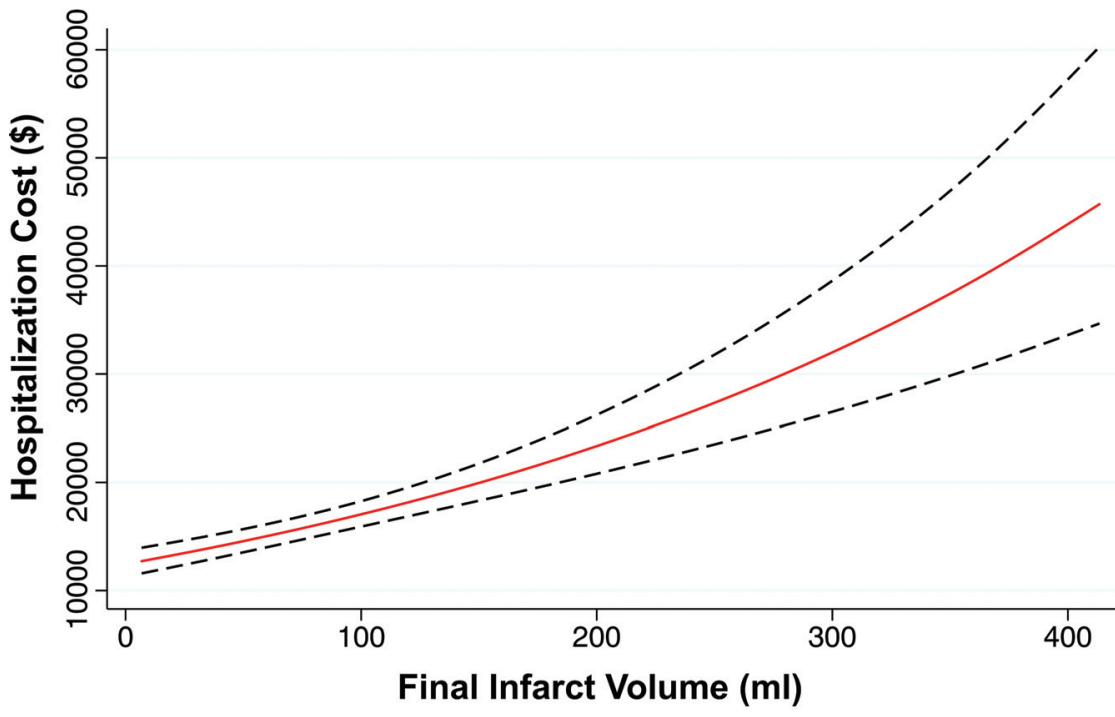

Legend: —xpected Cost - - - - 95\% Confidence Interval
2.0-mL infarct (fifth percentile). Under this hypothetic scenario, with the mean hospitalization cost of $\$ 20,351.23$ as a reference point, such a change in FIV would increase hospitalization costs by $\$ 30,244.13$, or $\$ 122.35$ for each additional milliliter of stroke burden (Table 4). Notably, in our analyses, the relationship between cost and FIV is exponential rather than linear, meaning that larger increases in FIV have a more pronounced impact (Fig 2). Another consideration is that our primary objective was to accurately identify critical predictors of increased ACLVO acute care hospitalization costs. By excluding costs that were highly variable (ie, physicians' costs) or occurring at random (ie, transfer costs) from the model, we improved our ability to correctly identify consistent predictors of hospitalization costs but under-represented the total cost to the hospital.

In addition to FIV, we also found that PH1, baseline NIHSS, obstructive sleep apnea, age, and ipsilateral carotid stenosis were significant predictors of hospitalization costs in our primary analysis. With the exception of ipsilateral carotid stenosis, our findings are consistent with prior studies of cost or clinical outcome. ${ }^{11,13,23,24}$ Increased hospitalization costs in patients with ACLVO with ipsilateral carotid stenosis are presumably a consequence of additional expenses accrued from endarterectomy or carotid stent placement.

Differences in the cost models generated by our subgroup analysis may be explained by inherent differences among patient populations. For example, carotid stenosis was a significant predictor of hospitalization cost only in the endovascular therapy subgroup. Rates of carotid revascularization in patients with moderate or severe symptomatic carotid stenosis ranged from $100 \%$ in the endovascular group to $30 \%$ and $28 \%$ in the IV tPA-only and no rep-

FIG 2. Univariate analysis: cost versus final infarct volume.

tionally excluded postadmission variables such as length of stay, intubation, and decompressive craniectomy, we find it remarkable that our primary model still accounted for $42.07 \%$ of the total variance of (log-transformed) hospitalization costs. FIV alone accounted for $20.87 \%$ of the variance in hospitalization costs. When interpreted across the range of observed FIVs, a patient with a 249.2-mL infarct (95th percentile) would have a 148.61\% higher hospitalization cost than an otherwise identical patient with a erfusion therapy groups, respectively. This discrepancy is a result of our institutional practice of revascularizing all symptomatic carotid arteries during the initial hospitalization unless contraindicated by the risk of hemorrhagic conversion attributable to high FIV. Therefore, patients with larger strokes, such as those seen in the IV tPA-only and no reperfusion therapy subgroups, undergo carotid revascularization less frequently, decreasing the impact of carotid stenosis on acute care hospitalization costs. Conversely, 
Table 4: Expected cost burden per additional infarct volume ${ }^{a}$

\begin{tabular}{lccc}
\hline $\begin{array}{c}\text { Increased Stroke } \\
\text { Burden }(\mathbf{m L})\end{array}$ & $\begin{array}{c}\text { Expected Increase } \\
\text { in Hospitalization Cost }\end{array}$ & $\begin{array}{c}\text { Net Expected } \\
\text { Cost Increase }\end{array}$ & $\begin{array}{c}\text { Cost per Additional } \\
1 \mathbf{~ m L} \text { of Stroke Burden }\end{array}$ \\
\hline 1 & $0.37 \%$ & $\$ 75.11$ & $\$ 75.11$ \\
10 & $3.75 \%$ & $\$ 763.75$ & $\$ 76.38$ \\
50 & $20.23 \%$ & $\$ 4116.33$ & $\$ 82.33$ \\
100 & $44.54 \%$ & $\$ 9065.25$ & $\$ 90.65$ \\
150 & $73.78 \%$ & $\$ 15,015.15$ & $\$ 100.10$ \\
200 & $108.93 \%$ & $\$ 22,168.52$ & $\$ 110.84$ \\
$247.2^{\mathrm{b}}$ & $148.61 \%$ & $\$ 30,244.13$ & $\$ 122.35$ \\
300 & $202.00 \%$ & $\$ 41,108.50$ & $\$ 137.03$ \\
350 & $263.09 \%$ & $\$ 53,539.62$ & $\$ 152.97$ \\
400 & $336.52 \%$ & $\$ 68,485.11$ & $\$ 171.21$ \\
$413.3^{\mathrm{c}}$ & $358.44 \%$ & $\$ 72,946.41$ & $\$ 176.50$ \\
\hline
\end{tabular}

${ }^{a}$ With reference to mean cost $=\$ 20,351.23$ and primary multivariable analysis (Table 3 ), holding all variables constant while increasing the FIV.

${ }^{b}$ Range of FIVs observed (fifth-95th percentile).

' Full range of observed FIVs (0-100th percentile).

age was not a significant predictor of cost in the endovascular subgroup. A potential explanation for this finding is that only elderly patients with excellent baseline functional status were selected for endovascular stroke treatment.

Our subgroup of patients undergoing endovascular thrombectomy was treated before the publication of randomized controlled trials demonstrating the effectiveness of endovascular therapy. However, these randomized controlled trials did not meaningfully change our institutional practice, and our findings remain generalizable. The NIHSS scores and Alberta Stroke Program Early CT Scores of our endovascular therapy cohort are also comparable with those reported in recent endovascular stroke randomized controlled trials, and our patients were similarly screened for pretreatment functional independence. Additionally, the primary endovascular treatment technique used at our institution was the stent retriever, resulting in $>90 \% \mathrm{mTICI} 2 \mathrm{~b}$ or 3 reperfusion rates. We also studied a wide time window of stroke onset to treatment (interquartile range, 236-465 minutes) with $\sim 15 \%$ of the cohort having wake-up stroke (Tables 1 and 2 ). Finally, there have not been substantial changes in post thrombectomy medical care or substantial inflation that would impact the validity of our key findings.

One of the limitations of our study is that the findings may be specific to high-volume, tertiary referral, academic hospitals. However, while absolute costs may differ across hospitals, predictors of cost are likely to be similar because they are ultimately determinants of resource use. FIV is known to be associated with inpatient interventions such as tracheostomy, feeding tube placement, and decompressive craniectomy, which both add to hospitalization cost and prolong hospital admission. ${ }^{25,26}$ Further supporting this hypothesis, a post hoc exploratory analysis of our dataset demonstrated a clear, significant relationship $(P<.001)$ between increasing FIV and prolonged hospitalization (On-line Fig 1). Thus, we believe our findings should be applicable to a broad range of hospitals. Additionally, intermediate and longterm care, key components of stroke health care costs, were not taken into account in our analysis. In the Endovascular Therapy for Ischemic Stroke with Perfusion-Imaging Selection (EXTEND-IA) trial, Campbell et $\mathrm{al}^{9}$ reported that patients who received endovascular treatment had significantly lower FIVs and returned home earlier than the control group. Accordingly, it can be ex- trapolated that lower FIVs are likely to result in decreased intermediate and long-term health care costs, though this hypothesis requires further investigation. ${ }^{27}$

Another limitation is the 6- to 48hour time window used to calculate infarct volumes, which is a reflection of our clinical practice. We obtain early MR imaging scans on patients undergoing endovascular recanalization treatment to assess for hemorrhage and guide postintervention antithrombotic therapy, whereas patients without endovascular recanalization are scanned later for prognostication and management of cerebral edema. Patients receiving IV tPA undergo follow-up imaging 24 hours post-treatment per protocol, while the timing of imaging in patients who do not receive reperfusion therapy is determined on a case-by-case basis. Early imaging may result in an underappreciation of infarct volume. However, most scans obtained $<24$ hours from admission were either for patients having undergone endovascular recanalization or those not receiving reperfusion therapy who presented with large completed infarcts (On-line Fig 2); these patients are unlikely to experience substantial infarct growth. ${ }^{9}$ By standardizing our infarct volume calculations to scans obtained between 6 and 48 hours from admission, we limited potential inconsistency in infarct volume calculations attributable to more variable imaging timing and progression and/or resolution of cerebral edema. We acknowledge that the non-uniform timing of follow-up imaging may introduce imprecision into our calculations, but we do not believe it alters our fundamental findings.

A further limitation is that our findings only apply to ACLVO stroke. We intentionally excluded posterior circulation large-vessel occlusions because treatment paradigms in this patient population are not driven uniformly by high-level randomized clinical trial data. Additionally, it appears that in ACLVO stroke lesion location may not be tightly correlated with outcome. ${ }^{28}$ Outcomes and hospital admission complexity in posterior circulation stroke, however, may be more dependent on lesion location due to the ramifications of brain stem infarction on consciousness and respiratory drive. ${ }^{29}$

Finally, 99 patients were excluded from our primary analysis because of EWOC. Patients with EWOC represent a clinically distinct patient population, and their inclusion in our sensitivity analysis confounds the model. However, controlling for EWOC status produced the same fundamental finding with FIV the most robust predictor of increased hospitalization costs. Furthermore, although EWOC significantly decreases hospitalization costs, it remains a clinically undesirable outcome. Pursuing EWOC may be appropriate in a subset of patients with ACLVO, but ideally cost-effectiveness strategies target cost savings and improved clinical outcomes in parallel.

\section{CONCLUSIONS}

We found that FIV, a well-known predictor of stroke-related disability, ${ }^{7,10,21,22}$ was the strongest predictor of increased hospital- 
ization costs in ACLVO stroke at our institution. Furthermore, this relationship was exponential-that is, greater absolute increases in FIV have a considerably greater effect on cost. A notable strength of our cost analysis is the use of detailed patient-level cost data rather than traditional indirect accounting methods. Additionally, our study has a relatively large sample size and broad inclusion criteria and demonstrated consistent findings across primary, subgroup, and sensitivity analyses. To our knowledge, this is the first time that the fundamental relationship between FIV and hospitalization costs has been reported. This finding has considerable economic implications for the treatment of ACLVO stroke. Therapies that reduce FIV not only improve clinical outcomes, but may also be critical to providing cost-effective treatment.

\section{ACKNOWLEDGMENTS}

The authors would like to thank Jon Petrie for assistance in obtaining and interpreting institutional cost data.

Disclosures: Christopher D. Streib—RELATED: Grant: National Institutes of Health StrokeNet, Comments: National Institutes of Health StrokeNet Fellowship grant University of Pittsburgh (1U01NS086489-02).* Srikant Rangaraju-UNRELATED: Grants/Grants Pending: National Institutes of Health/National Institute of Neurological Disorders and Stroke K08.* Daniel G. Winger-RELATED: Grant: National Institutes of Health, Comments: The project described was supported by the National Institutes of Health through grant number ULI-TR-000005. * Tudor G. JovinUNRELATED: Consultancy: Cerenovus, Biogen; Stock/Stock Options: Anaconda, Silk Road, Route 92, Blockade Medical, FreeOx Biotech. Brian T. Jankowitz-UNRELATED: Consultancy: Stryker, Medtronic; *Money paid to the institution.

\section{REFERENCES}

1. Heidenreich PA, Trogdon JG, Khavjou OA, et al; American Heart Association Advocacy Coordinating Committee, Stroke Council, Council on Cardiovascular Radiology and Intervention, Council on Clinical Cardiology, Council on Epidemiology and Prevention, Council on Arteriosclerosis, Thrombosis and Vascular Biology, Council on Cardiopulmonary, Critical Care, Perioperative and Resuscitation, Council on Cardiovascular Nursing, Council on the Kidney in Cardiovascular Disease, Council on Cardiovascular Surgery and Anesthesia, and Interdisciplinary Council on Quality of Care and Outcomes Research. Forecasting the future of cardiovascular disease in the United States: a policy statement from the American Heart Association. Circulation 2011;123:933-44 CrossRef Medline

2. Smith WS, Lev MH, English JD, et al. Significance of large vessel intracranial occlusion causing acute ischemic stroke and TIA. Stroke 2009;40:3834-40 CrossRef Medline

3. Rai AT, Evans K, Riggs JE, et al. Intravenous thrombolysis of large vessel occlusions is associated with higher hospital costs than small vessel strokes: a rationale for developing stroke severity-based financial models. J Neurointerv Surg 2016;8:423-28 CrossRef Medline

4. Nogueira RG, Jadhav AP, Haussen DC, et al; DAWN Trial Investigators. Thrombectomy 6 to 24 hours after stroke with a mismatch between deficit and infarct. $N$ Engl J Med 2018;378:11-21 CrossRef Medline

5. Albers GW, Marks MP, Kemp S, et al; DEFUSE 3 Investigators. Thrombectomy for stroke at 6 to 16 hours with selection by perfusion imaging. N Engl J Med 2018;378:708-18 CrossRef Medline

6. Saver JL, Goyal M, Bonafe A, et al; SWIFT PRIME Investigators. Stent-retriever thrombectomy after intravenous t-PA vs. t-PA alone in stroke. N Engl J Med 2015;372:2285-95 CrossRef Medline

7. Jovin TG, Chamorro A, Cobo E, et al; REVASCAT Trial Investigators. Thrombectomy within $\mathbf{8}$ hours after symptom onset in ischemic stroke. N Engl J Med 2015;372:2296-306 CrossRef Medline
8. Goyal M, Demchuk AM, Menon BK, et al; ESCAPE Trial Investigators. Randomized assessment of rapid endovascular treatment of ischemic stroke. $N$ Engl J Med 2015;372:1019-30 CrossRef Medline

9. Campbell BC, Mitchell PJ, Kleinig TJ, et al; EXTEND-IA Investigators. Endovascular therapy for ischemic stroke with perfusion-imaging selection. N Engl J Med 2015;372:1009-18 CrossRef Medline

10. Berkhemer OA, Fransen PS, Beumer D, et al; MR CLEAN Investigators. A randomized trial of intraarterial treatment for acute ischemic stroke. $N$ Engl J Med 2015;372:11-20 CrossRef Medline

11. Simpson KN, Simpson AN, Mauldin PD, et al; IMS III Investigators. Drivers of costs associated with reperfusion therapy in acute stroke: the Interventional Management of Stroke III Trial. Stroke 2014;45: 1791-98 CrossRef Medline

12. Wang G, Joo H, Tong $X$, et al. Hospital costs associated with atrial fibrillation for patients with ischemic stroke aged 18-64 years in the United States. Stroke 2015;46:1314-20 CrossRef Medline

13. Wang G, Zhang Z, Ayala C, et al. Costs of hospitalization for stroke patients aged 18-64 years in the United States. J Stroke Cerebrovasc Dis 2014;23:861-68 CrossRef Medline

14. Huang YC, Hu CJ, Lee TH, et al. The impact factors on the cost and length of stay among acute ischemic stroke. J Stroke Cerebrovasc Dis 2013;22:e152-158 CrossRef Medline

15. Brinjikji W, Rabinstein AA, Cloft HJ. Hospitalization costs for acute ischemic stroke patients treated with intravenous thrombolysis in the United States are substantially higher than Medicare payments. Stroke 2012;43:1131-33 CrossRef Medline

16. Brinjikji W, Kallmes DF, Rabinstein AA, et al. Hospitalization costs for patients with acute ischemic stroke treated with endovascular embolectomy in the United States. Stroke 2011;42:3271-73 CrossRef Medline

17. Jones SA, Gottesman RF, Shahar E, et al. Validity of hospital discharge diagnosis codes for stroke: the Atherosclerosis Risk in Communities Study. Stroke 2014;45:3219-25 CrossRef Medline

18. Chen M. Cost-effectiveness of endovascular therapy for acute ischemic stroke. Neurology 2012;79:S16-21 CrossRef Medline

19. Boulton C. UPMC Selling Analytics to Curb Health Care Costs. Wall Street Journal. April 28, 2014. http://blogs.wsj.com/cio/2014/04/28/ upmc-builds-analytics-to-curb-health-care-costs/. Accessed May 20, 2015

20. Rangaraju S, Liggins JT, Aghaebrahim A, et al. Pittsburgh outcomes after stroke thrombectomy score predicts outcomes after endovascular therapy for anterior circulation large vessel occlusions. Stroke 2014;45:2298-304 CrossRef Medline

21. Ribo M, Flores A, Mansilla E, et al. Age-adjusted infarct volume threshold for good outcome after endovascular treatment. J Neurointerv Surg 2014;6:418-22 CrossRef Medline

22. Zaidi SF, Aghaebrahim A, Urra X, et al. Final infarct volume is a stronger predictor of outcome than recanalization in patients with proximal middle cerebral artery occlusion treated with endovascular therapy. Stroke 2012;43:3238-44 CrossRef Medline

23. Mansukhani MP, Bellolio MF, Kolla BP, et al. Worse outcome after stroke in patients with obstructive sleep apnea: an observational cohort study. J Stroke Cerebrovasc Dis 2011;20:401-05 CrossRef Medline

24. Rao NM, Levine SR, Gornbein JA, et al. Defining clinically relevant cerebral hemorrhage after thrombolytic therapy for stroke: analysis of the National Institute of Neurological Disorders and Stroke tissue-type plasminogen activator trials. Stroke 2014;45:2728-33 CrossRef Medline

25. Walcott BP, Miller JC, Kwon CS, et al. Outcomes in severe middle cerebral artery ischemic stroke. Neurocrit Care 2014;21:20-26 CrossRef Medline

26. Thomalla G, Hartmann F, Juettler E, et al; Clinical Trial Net of the German Competence Network Stroke. Prediction of malignant middle cerebral artery infarction by magnetic resonance imaging within 6 hours of symptom onset: a prospective multicenter 
observational study. Ann Neurol 2010;68:435-45 CrossRef Medline

27. Leppert MH, Campbell JD, Simpson JR, et al. Cost-effectiveness of intra-arterial treatment as an adjunct to intravenous tissue-type plasminogen activator for acute ischemic stroke. Stroke 2015;46: 1870-76 CrossRef Medline

28. Rangaraju S, Streib C, Aghaebrahim A, et al. Relationship between lesion topology and clinical outcome in anterior circulation large vessel occlusions. Stroke 2015;46:1787-92 CrossRef Medline

29. Campbell D, Rangaraju S, Streib C, et al. Pittsburgh Outcomes After Stroke Thrombectomy Vertebrobasilar (POST VB) score predicts outcomes after endovascular therapy for basilar artery occlusions. In: Proceedings of the International Stroke Conference, San Diego, California; February 12-14, 2014 